\title{
Fiebre entérica \\ por Pseudomonas Stutzeri
}

\author{
T. M. CRISTINA NUNEZ *, T. M. LUIS ZAROR*, DR. RICHARD RIOS **
}

El género Pseudomonas agrupa muchas especies, la mayor parte de ellas fitopatógenas (1). Existe un grupo de especies capaz de producir enfermedad en el hombre siendo la Pseudomonas aeruginosa la de mayor aislamiento en microbiología médica, sin embargo, aquellas de menor frecuencia de aislamiento en la práctica médica y que tienen un rol patógeno incierto, han sido objeto de numerosas investigaciones en los últimos años (2) (3) (4) (5).

A este grupo pertenece las Pseudomonas stutzeri que ha sido aislada en diferentes localizaciones en el hombre. Fue descrita en 1895 por Burry y Stutzer (6) y denominada Bacillus desnitrificans II, señalando como fuentes de aislamiento el estiércol, el humus y el heno. Con posterioridad a la publicación de Van Niel y Allen en 1952 (7), algunos autores han hecho referencia a este microorganismo que ha sido aislado con mayor frecuencia en cuadros de septicenias, (8) a partir uno de los cuales nosotros también lo hemos aislado.

La Pseudomonas stutzeri es un bacilo Gram negativo no esporulado, aerobio, móvil por flagelación monótrica.

Las colonias en agar tryptosa son adherentes y presentan inicialmente un aspecto seco y verrucoso semejando un cráter de bordes elevados con un pequeño halo de diseminación, pudiendo la colonia tomar posteriormente un aspecto mucoide.

Las reacciones bioquímicas se detallan en la tabla 1.

Aunque las fuentes de infección no están bien establecidas, creemos que un mayor conocimien-

\footnotetext{
* Instituto de Microbiología Clinicá. Facultad de Medicina.

Universidad Austral de Chile - Valdivia.

* Servicio de Pediatría. Sección Infecciosos. Hospital Regional de Valdivia.

Trabajo de ingreso a la Sociedad Chilena de Pedlatría, presentado en las IV Jornadas Anuales en Valdivia (16-19 Octubre, 1974).
}

to acerca de las características de este microorganismo puede permitir en el futuro aislamientos más frecuentes en muestras clínicas contribuyendo al mismo tiempo al esclarecimiento de su rol patógeno y a la detección de sus reservorios.

\section{CASO CLINICO (Obs. 131840) - Abril de 1973.}

Escolar de sexo femenino de 14 años de edad, proveniente de un medio socio económico bajo, con malas condiciones higiénico sanitarias, que consulta por síndrome febril de una semana de evolución, de carácter insidioso que al tercer día de enfermedad se acompaña de síntomas digestivos caracterizado por dolor abdominal tipo cansado, de Iocalización peri umbical y constipación pertinaz. Previo a su ingreso se agrega odinofagia y tos irritativa. No acusaba enfermedades infecciosas previas, ni contacto de tuberculosis.

Al examen físico, los hechos positivos eran: regular estado general y nutritivo, cicatriz BCG y presencia en la parte alta del abdomen de múltiples elementos petequiales que se interpretaron como picadura de pulga y que desaparecen al quinto día de su ingreso.

En el resto del examen segmentario había: una lengua saburral de bordes limpios y húmedos, mucosa faríngea congestiva y el abdomen se presentaba meteorizado, gorgoteo en hemiabdomen derecho, y un bazo que se percutía aumentado sin lograrse palpar y que al $6^{\circ}$ día se negativiza. Resto del examen negativo. En virtud del cuadro clínico se plantean los siguientes diagnósticos: Síndrome febril; probable Fiebre tifoidea, y se solicitan exámenes en tal sentido.

Hemograma: Leucocitos 8.000, Basófilos 0, Eosinófilos 1, Mielocitos 0, Juveniles 0, Baciliformes 9, Segmentados 51, Linfocitos 29, Monocitos 10, Plaquetas: Abundantes al frotis. Hematocrito: $34 \%$, Hemoglobina $66 \%$.

Sedimentación $113 \mathrm{~mm} / \mathrm{hora}$.

Hemocultivo seriado: se informa "Bacilo Gram ne- 
TABLA 1

CARACTERISTICAS MORFOLOGICAS, CULTURALES, Y BIOQUIMICAS DE PSEUDOMONAS STUTZERI

\begin{tabular}{|c|c|c|c|}
\hline Características & Interpretación & Caracteristicas & Interpretación \\
\hline Forma & bacilo & Oxidasa & + \\
\hline Gram & $(-)$ & Glucosa & $+\mathrm{A}$ \\
\hline Espora & $(-)$ & Lactosa & Alcalina \\
\hline Motilidad & + & Sacarosa & Alcalina \\
\hline Flagelo & 1 & Manita & $+A$ \\
\hline Cápsula & - & Maltosa & $+\mathrm{A}$ \\
\hline Tempratura & & D. Xilosa & $+\mathrm{A}$ \\
\hline $25^{\circ} \mathrm{C}$ & + & Indol & $(-)$ \\
\hline $37^{\circ} \mathrm{C}$ & + & Red. $\mathrm{NO}_{3}-\mathrm{NO}_{2}$ & + con gas \\
\hline $42^{\circ} \mathrm{C}$ & - & Citrato & + \\
\hline Pigmento & amarillo & $\mathrm{H}_{2} \mathrm{~S}$ papel & - \\
\hline Hemólisis & - & $\mathrm{H}_{2} \mathrm{~S}$ Kliger & - \\
\hline Desarrolo en: & & Leche Tornas. & Alcalina \\
\hline Mac Conkey & $+f$ & Hidrolisis esculina & $(-)$ \\
\hline SS & + & D. Lisina & $(-)$ \\
\hline Cetrimida & + & D. Ornitina & $(-)$ \\
\hline Catalasa & + & D. Arginina & $(+)$ \\
\hline
\end{tabular}

gativo en estudio" y sensibilidad a las drogas antimicrobianas. Con posterioridad al alta se logra su identificación.

Urocultivo y coprocultivo nada significativo.

Reacciones serológicas seriadas semanales en 3 oportunidades negativas.

A las $48 \mathrm{hrs.} \mathrm{de} \mathrm{su} \mathrm{ingreso} \mathrm{se} \mathrm{inicia} \mathrm{terapia} \mathrm{con}$ Cloramfenicol de acuerdo al esquema nacional para fiebre tifoídea, terapia que se mantiene a pesar del informe de resistencia al Cloramfenicol del antibiograma cualitativo, lográndose apirexia por lisis a las $72 \mathrm{hrs}$. y continuando afebril hasta su alta (149 día). Post alta su evolución fue satisfactoria. El estudio ulterior de la sensibilidad cuantitativa al cloramfenicol demostró una concentración mínima inhitoria para esta droga de $\mathbf{5 0}$ microgramos por $\mathrm{ml}$. de medio de cultivo.

Frente a esta paciente existían una serie de hechos clínicos que a su ingreso llevaron a plantear una probable fiebre tifoídea; a saber el antecedente epidemiológico en cuanto a su procedencia y deplorable condición de saneamiento, el cuadro clínico relatado y los hallazgos semiológicos.

Si bien el Laboratorio a través del hemograma y la sedimentación no concordaba con lo que es dable esperar en estos casos, la presencia de eosinófilos se interpretó como una fórmula de 2 a semana de evolución y la negatividad de las reacciones serológicas se atribuyó a los pacientes que cursan su enfermedad con Reacción de Widal negativa.

Esta hipótesis diagnóstica se vio reforzada por la respuesta clínica que fue típica para lo que se ve en fiebre tifoídea. Sin embargo, el estudio bacteriológico para Salmonella typhi fue negativo resultando los dos hemocultivos seriados positivos para Pseudomonas stutzeri, el cual sería el agente etiológico del cuadro clínico descrito, actuando como patógeno primario.

Por no haberse descrito en nuestro medio, por el desconocimiento de su taxonomía y de los cuadros clínicos que es capaz de producir como patógeno primario o como oportunista, hemos creído de interés reportar este caso máxime cuando es posible esperar que algunos casos clínicos en los que no se logra identificación bacteriológica final pudieran ser atribuídos a este germen.

\section{RESUMEN}

Presentamos un caso de septicemia por Pseudomonas stutzeri, que clínicamente fue diagnosticado como una fiebre tifoídea. Se describen las características de cultivo y bioquímicas de este microorganismo.

\section{SUMMARY}

We describe a case of septicemia produced by Pseudomonas stutzeri that clinically was diagnosed as a thyphoid fever. We also describe the cultural and biochemical characteristics of this bacteria. 


\section{REFERENCIAS}

1. Breed, R. S.; Murray, F. G. D. and Hitchens, A. P. Bergey's Manual of determinative Bacteriology. Williams and Wilkins Co. Baltimore. 7th. Ed. 1957.

2. Sutter, V. L. Identification of Pseudomonas species isolated from hospital environment and human sources, Appl. Microb. 16, 10: 1352 - 1358. 1968.

3. Blazevich, D. J.; Koepcke, M. H. and Matsen, J. M. Incidence and identification of Pseudomonas fluorescens and Pseudomonas putida in the Clinical Laboratory. Appl. Microb. 25, 1: $107-110.1973$.

4. Farkas - Himsley, H. and Beastall, S. Selection and rapid identification of Pseudomonas pseudomallei from other Gram negative bacteria. Am J. Clin. Pathol. 49, 6: 850 - 856, 1968.

5. Gilardi, G. L. Characterization of Pseudomonas species isolated from Clinical specimens. Appl. Microb. 21: 414 - 419, 1971.

6. Burri, R. and Stutzer. A. Ueber nitratzerstoerende Bakterien und den durch dieselben bedington Stickstoffverlust. Zentralbl. Bakt., Abt. II, 1: $251-256$, $350-364,392-398,422-432,1895$. Citado por Von Graevenitz A. Am. J. Clin. Path. 43, 4. 1965.

7. Van Niel, C. B. and Allen, M. B. A note on Pseudomonas stutzeri. J. Bacteriol. 64: 413 - 422, 1952.

8. Von Graevenitz, A. Pseudomonas stutzeri isolated from Clinical specimens. Am. J. Clin. Pathol. 43, 4: $357-360.1965$. 